\title{
AVALIAÇÃO DO CONFORTO TÉRMICO EM APARTAMENTOS OCUPADOS EM FLORIANÓPOLIS
}

\section{EVALUATION OF THERMAL COMFORT IN OCCUPIED APARTMENTS IN FLORIANÓPOLIS}

\author{
Camila Ferreira da Silva (IFSC); \\ Ana Lígia Papst de Abreu, Dra. (IFSC) \\ Palavras Chave \\ Conforto Térmico; Carta Bioclimática; Avaliação Bioclimática de Edificações
}

\section{Key Words}

Thermal Comfort; Givoni Bioclimatic Chart; Buildings Bioclimatic Analysis

\section{RESUMO}

As principais estratégias bioclimáticas para edificações em Florianópolis é a ventilação e o uso de massa térmica com aquecimento solar. $\mathrm{O}$ objetivo desta pesquisa é verificar o conforto térmico de ambientes reais em uso, comparado ao conforto térmico externo. O método está dividido em três partes: (a) caracterização dos apartamentos monitorados, mostrando que atendem às estratégias bioclimáticas; (b) equipamentos usados durante um ano de medição das temperaturas e umidades; (c) determinação percentual das horas em conforto (interno e externo) usando o software Analysis Bio. Os resultados obtidos para os apartamentos estudados mostram que percentualmente ocorreu mais horas de conforto térmico nos ambientes internos se comparado ao ambiente externo. Mas o desconforto por calor, no período analisado, foi superior em alguns ambientes internos do que ao ambiente externo.

\section{ABSTRACT}

There are two main bioclimatic strategies for buildings in Florianópolis: natural ventilation, and thermal mass with solar heating. The objective of this research is to verify the thermal comfort in occupied apartments, comparing with the external thermal comfort. The method is divided into three parts: (a) characterization of the monitored environments, showing their according with the bioclimatic strategies; (b) equipment that were used during a year of measuring of temperatures and humidities; (C) determination of percental of hours in comfort (internal and external) using Analysis Bio software. The results obtained show that the percental of hours of comfort occurred indoor when compared to the external environment; although, thermal discomfort due high temperatures and humidity, during the analyzed period, was higher in some rooms of two apartments than in the external environment. 


\section{INTRODUÇÃO}

As construções além de proteção a intempéries, precisam garantir ao ser humano o conforto térmico, mesmo em condições climáticas adversas. $O$ conforto térmico dá-se em um conjunto de variáveis ambientais e fisiológicas. As principais variáveis ambientais para o conforto térmico estão diretamente relacionadas a temperatura, umidade, velocidade do ar e radiação incidente. As fisiológicas, atendem as exigências humanas, e estão relacionadas ao funcionamento do organismo humano (FROTA; SCHIFFER, 2000).

A American Society of Heating, Refrigeration and Air Conditioning Engineers (ASHRAE, 2010) define conforto térmico como o estado da mente que expressa satisfação do homem com o ambiente térmico que o circunda. Muitos estudos vêm sendo realizados sobre conforto térmico, devido a mudança climática que está ocorrendo no mundo. Estudos que desenvolvem índices de conforto térmico para o ser humano procuram determinar os graus de conforto ou desconforto por frio ou calor, variando alguns dos parâmetros e as condições que podem proporcionar sensações semelhantes (FROTA; SCHIFFER, 2000).

Conhecendo-se os fatores e os limites de conforto térmico humano, este pode ser buscado dentro de uma edificação através do uso de medidas passivas: ventilação cruzada; sombreamento; medidas que englobam as características da edificação, como orientação, forma, disposição das aberturas, envoltória, cor da parede, cobertura, entre outros; e medidas ambientais (CHAVES et all., 2016).

A NBR 15.220 (ABNT, 2003) subdivide o Brasil em oito zonas bioclimáticas, e define as características principais dessas zonas e dá diretrizes construtivas para cada uma dessas zonas. Florianópolis encontra-se na zona bioclimática três, tendo como principais estratégias bioclimáticas para as edificações: ventilação e aquecimento solar com massa térmica nas vedações. O programa Analysis Bio desenvolvido na UFSC, permite que os dados de temperatura e umidade relativa sejam plotados sobre a carta bioclimática adaptada de Givoni (GOULART et al., 1994), e calcula a porcentagem de horas do ano em conforto ou não, e qual estratégia construtiva mais apropriada para alcançar a sensação de conforto.

Este trabalho buscou medir a temperatura e umidade de apartamentos ocupados, durante o período de um ano, sem interferir na sua utilização. Estas residências atendem aos critérios das estratégias bioclimáticas para Florianópolis, e possuem todas a mesma configuração de planta, mas com diferentes orientações solares e ocupações.

O objetivo deste artigo é verificar o atendimento ao conforto térmico de apartamentos em uso na cidade de Florianópolis, comparando ao conforto térmico externo à edificação.

\section{REVISÃO BIBLIOGRÁFICA}

$O$ conforto térmico depende de uma série de fatores fisiológicos associados a fatores ambientais, como velocidade do vento, temperatura do ar, umidade relativa do ar entre outros (RUPP; VÁSQUEZ; LAMBERTS, 2015). Além dessas variáveis, também se tem a atividade física e a vestimenta que interferem no conforto térmico do indivíduo (LAMBERTS; DUTRA; PEREIRA, 2014).

Segundo Buriol et. al. (2015) o clima de uma região está entre o principal fator que condiciona o comportamento humano, esse interfere principalmente na alimentação, vestimenta e tipo de atividade que o indivíduo realiza.

Está em proposição uma norma brasileira sobre condições de conforto térmico humano em ambientes onde são especificadas “(...) as combinações de variáveis térmicas ambientais e pessoais que produzam condições aceitáveis para a maioria dos ocupantes (...)" (LAMBERTS et all. 2013, pg. 82). E comenta ainda que "(...) as condições ambientais que resultam em conforto não são as mesmas para todos." (LAMBERTS, et all. 2013, pg.81).

Além disso, a expectativa de conforto térmico é diferente para ambientes que sejam naturalmente ventilados (onde os usuários podem abrir ou fechar as janelas), e para ambientes condicionados artificialmente (ASHRAE, 2013). Givoni (1992) comenta que pessoas que moram em ambientes naturalmente ventilados (sem condicionamento de ar artificial) aceitam maiores variações de temperatura e velocidade do ar. Este mesmo pesquisador propôs uma ferramenta (carta bioclimática de Givoni) onde a partir dos dados climáticos do local (temperatura e umidade) sobre uma carta psicrométrica, é possível identificar as principais estratégias de arquitetura para a edificação se adequar ao clima.

A NBR 15.575 (ABNT, 2013) é a primeira norma brasileira que trata da avaliação do desempenho da edificação habitacional com foco no atendimento das expectativas dos usuários com relação a conforto e segurança no uso. Com relação ao conforto térmico no verão, esta norma determina que a edificação deve ter um desempenho térmico "Mínimo", onde a temperatura interna máxima nos ambientes de permanência prolongada (salas e dormitórios) tem de ser inferior a temperatura externa máxima. Para um desempenho térmico "Mínimo" de inverno, os ambientes de permanência prolongada têm de apresentar temperatura interna mínima $3^{\circ} \mathrm{C}$ acima da temperatura mínima externa. Um dia típico de verão em Florianópolis tem temperatura máxima diária de $32,7^{\circ} \mathrm{C}$, e um dia típico de inverno tem temperatura mínima diária de $6,0^{\circ} \mathrm{C}$. A NBR 15.575 não traz nenhuma referência 
se as temperaturas máxima e mínima interna têm de serem medidas em ambientes em uso ou desocupados, com ventilação natural ou com uso de condicionadores de ar. Outro detalhe a se destacar é que a temperatura máxima para um ambiente dito confortável usando a carta Bioclimática de Givoni é de $28^{\circ} \mathrm{C}, 4,7^{\circ} \mathrm{C}$ abaixo do que determina a NBR 15.575 como "Mínimo". Como temperatura mínima de conforto térmico no período frio, no método de Givoni é de $18^{\circ} \mathrm{C}$, enquanto pela NBR 15.575, o ambiente interno em Florianópolis poderia chegar a $9^{\circ} \mathrm{C}\left(6^{\circ} \mathrm{C}+3^{\circ} \mathrm{C}\right)$.

Para este estudo optou-se pela utilização da carta bioclimática de Givoni, que é uma adaptação sobre a carta psicrométrica, no qual são propostas estratégias construtivas para adequar a construção ao clima. Os dados de temperatura e umidade do ar sobre o diagrama psicrométrico, permitem determinar quais estratégias bioclimáticas indicadas para uma determinada localidade. (LAMBERTS; DUTRA; PEREIRA, 2014).

Sendo assim, para obtenção das cartas bioclimáticas surgiu a necessidade da criação de ferramentas auxiliares. Segundo Miranda et. al. (2010) devido à complexidade das variáveis envolvidas para a abordagem bioclimática, várias ferramentas vêm sendo aprimoradas: gráficos de insolação; diagramas de sombras; entre outros. Atualmente as ferramentas são de forma digital, como é o caso do Analysis Bio. O programa Analysis Bio foi desenvolvido por pesquisadores do Laboratório de Eficiência Energética em Edificações da Universidade Federal de Santa Catarina (LABEEE/UFSC) e é uma ferramenta para a obtenção de estratégias bioclimáticas, tendo como referência a carta bioclimática de Givoni para países em desenvolvimento. O programa Analysis Bio caracteriza-se dessa forma, como ferramenta de auxílio nas fases iniciais de projetos, assim como, ferramenta complementar nos processos de simulação computacional (MIRANDA et. al. 2010). Através da carta bioclimática de Givoni é possível saber se em função de determinada temperatura e umidade do ar as pessoas estariam em conforto, ou desconforto térmico, por exemplo.

Segundo Lamberts, Dutra e Pereira (2014) quando Givoni concebeu a metodologia da Carta Bioclimática, a entrada de dados era para ser a temperatura e a umidade interna das edificações. Com os dados das temperaturas e umidades internas sobre a carta psicrométrica poderia se observar qual a estratégia construtiva indicada para que a edificação fosse adequada e desta forma poder garantir o conforto térmico dos seus ocupantes. Na Figura 1 observa-se que os dados de entrada podem ser a umidade relativa, a umidade absoluta ou a temperatura de bulbo úmido, junto com a temperatura de bulbo seco (temperatura do ar). A Figura 1 também apresenta esquematicamente as oito estratégias bioclimáticas propostas por Givoni, separadas em zonas, para alcançar o conforto térmico na edificação, além da delimitação da própria zona de conforto na carta psicrométrica. As zonas bioclimáticas a direita e acima da zona de conforto apresentam valores de temperatura e umidade que causam desconforto térmico por calor. As zonas bioclimáticas a esquerda da zona de conforto, são zonas onde os dados de temperatura causariam desconforto por frio.

Figura 01: Carta Bioclimática esquemática de Givoni com separação das nove zonas de estratégias bioclimáticas.

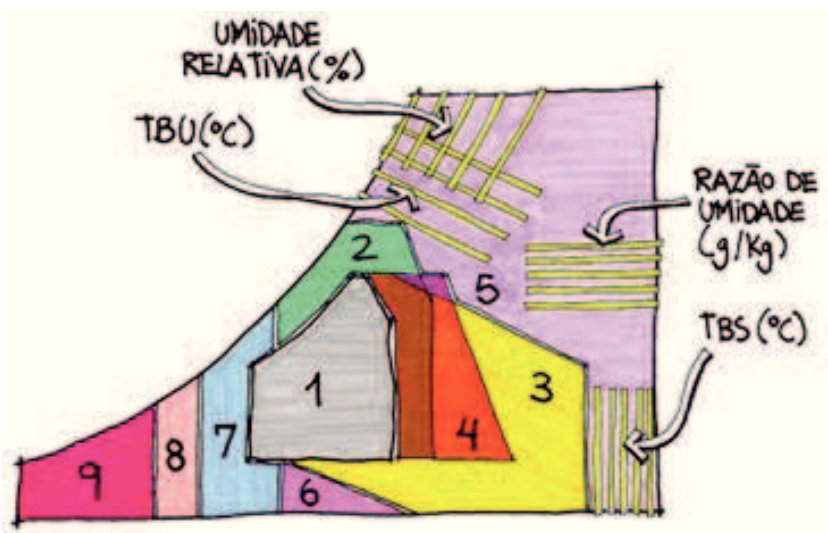

Fonte: Luciano Dutra $\odot$

As nove zonas apresentadas na Figura 1 são: 1 - conforto térmico;

2 - ventilação $(\mathrm{V})$;

3 - resfriamento evaporativo (RE);

4 - massa térmica para resfriamento $(M R)$;

5 - ar-condicionado (AC);

6 - umidificação $(U)$;

7 - massa térmica para aquecimento (MA);

8 - aquecimento solar passivo (AS);

9 - aquecimento artificial (AA).

O software Analysis Bio permite plotar os dados horários de temperatura e umidade de um ano inteiro. Lamberts, Dutra e Pereira (2014) usaram o software para plotar os dados de temperatura e umidade do Ano Climático de Referência (Test Reference Year - TRY), que são dados medidos em aeroportos (ou seja, dados externos) para indicar quais são as principais estratégias construtivas para o clima de diversas cidades brasileiras. Desta forma a proposta da utilização da Carta Bioclimática de Givoni é servir de ferramenta para as 
primeiras tomadas de decisões de um projeto que seja adaptado ao clima.

A Figura 02 apresenta a imagem da carta bioclimática de Givoni plotada com o ano climático de referência (TRY - Test Reference Year) de Florianópolis. Um ano climático de referência é um ano típico de dados climáticos do local, ele é selecionado entre vários anos de medições climáticas, eliminando os anos de dados com temperaturas médias mensais extremas. (GOULART et all, 1998). Como resultado o software Analysis Bio apresenta que $79 \%$ das horas do ano climático de referência estão na zona de desconforto, sendo 38\% das horas desconforto por calor e $41 \%$ desconforto por frio, sobrando assim $21 \%$ de horas de conforto. As principais estratégias construtivas para evitar o desconforto por calor são o uso da ventilação em $35,5 \%$ das horas do ano, e o desconforto por frio nas edificações é amenizado em 35,4\% das horas do ano pela adoção de massa térmica e aquecimento solar (LAMBERTS; DUTRA; PEREIRA, 2014).

Figura 02: Carta Bioclimática de Florianópolis com dados de ano climático de referência.

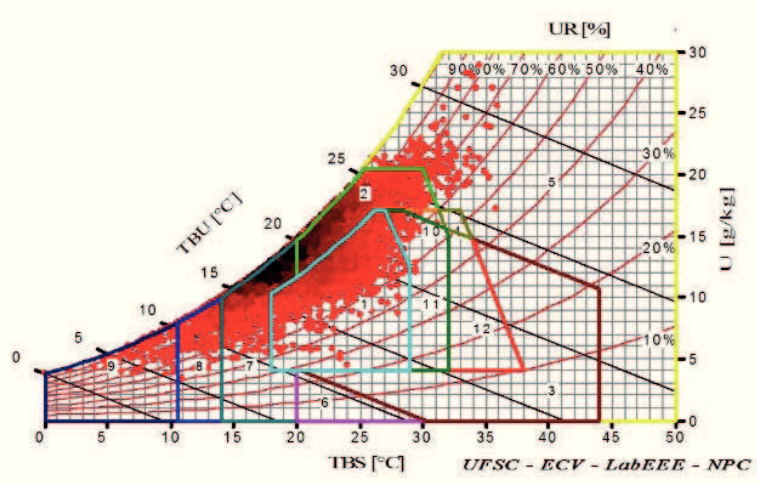

Fonte: Lamberts et al (2014).

De acordo com Souza e Rodrigues (2012), a utilização da ventilação natural como estratégia para o conforto térmico é importante, e num projeto que a ventilação natural é necessária, deve-se avaliar em detalhes as condições climáticas e as condições locais.

Os valores de abertura mínimo em um ambiente são de 1/6 (16,67\%) da área do piso segundo o Código de Obras de Florianópolis (CÂMARA MUNICIPAL DE FLORIANÓPOLIS, 2000), mas sem especificar se é para ventilação ou para iluminação. No RTQ-R (Regulamento Técnico da Qualidade para o Nível de Eficiência Energética de Edificações Residenciais) é feita esta diferenciação, onde a área efetiva para ventilação é a "parcela de área do vão que permite a passagem de ar" (INSTITUTO NACIONAL DE METROLOGIA E QUALIDADE INDUSTRIAL, 2012). Pelo
RTQ-R percentual de área mínimo para ventilação em relação à área útil do ambiente é de $8 \%$. Logo, se todas as edificações aprovadas para construção em Florianópolis atendem ao valor mínimo do Código de Obras, e usarem janelas de correr, estas atendem também ao RTQ-R. O conceito de ventilação cruzada pode ser usado para uma unidade autônoma ou para um ambiente, desde que a unidade ou o ambiente possua aberturas em duas fachadas de orientações diferentes.

Para se ter uma ideia quantitativa da massa térmica a ser utilizada $m$ Florianópolis, buscou-se o que é preconizado pela NBR 15.575 (ANBT, 2013). A NBR 15.575 (ABNT, 2013) estabelece requisitos e critérios para que uma edificação tenha o mínimo desempenho exigido pelos usuários. Com relação ao desempenho térmico, esta norma possui duas formas de verificação ao seu atendimento: (i) através dos sistemas construtivos de vedações verticais e coberturas com relação aos critérios de transmitância térmica e capacidade térmica; (ii) através da verificação de temperaturas internas em edificações (ou protótipos em tamanho real), ou simulações computacionais. A Tabela 01 é um resumo dos valores de transmitância térmica e capacidade térmica para a zona bioclimática onde está situada Florianópolis.

Tabela 01: - Valores de Transmitância térmica e capacidade térmica para vedações verticais.

\begin{tabular}{|c|c|c|}
\hline \multicolumn{2}{|c|}{ Transmitância Térmica (U) } & $\begin{array}{c}\text { Capacidade } \\
\text { Térmica }(\mathrm{C})\end{array}$ \\
\hline $\mathrm{a} \leq 0,6$ & $\mathrm{a}>0,6$ & $\mathrm{C} \geq 130 \mathrm{~kJ} /\left(\mathrm{m}^{2} . \mathrm{K}\right)$ \\
\hline $\mathrm{U} \leq 3,7 \mathrm{~W} /\left(\mathrm{m}^{2} . \mathrm{K}\right)$ & $\begin{array}{c}\mathrm{U} \leq 2,5 \mathrm{~W} / \\
\left(\mathrm{m}^{2} . \mathrm{K}\right)\end{array}$ & \\
\hline $\begin{array}{l}\text { *a é a absortância à radiação solar da superfície externa } \\
\text { da parede. }\end{array}$ \\
\hline
\end{tabular}

Fonte: adaptado da NBR 15.575 (ABNT, 2015b)

\section{MATERIAIS E MÉTODOS}

O método está dividido em três partes: (a) caracterização dos ambientes; (b) equipamentos usados; (c) determinação percentual das horas em conforto.

\subsection{Caracterização do ambiente}

As medições foram realizadas em um condomínio multifamiliar, no qual foi possível trabalhar com apartamentos com a mesma planta (Figura 03), porém com orientações solares diferentes. Foram dois os ambientes monitorados por apartamento: a suíte e a sala. Estes ambientes têm somente uma abertura por ambiente e as aberturas da sala e da suíte estão na mesma orientação 
solar. A suíte tem paredes em duas orientações solares diferentes. Os três apartamentos monitorados não pertencem ao mesmo bloco e não estão localizados todos mesmo andar, mas evitou-se apartamentos do último andar devido a carga térmica da cobertura.

Figura 03: Croqui da Planta baixa do apartamento tipo.

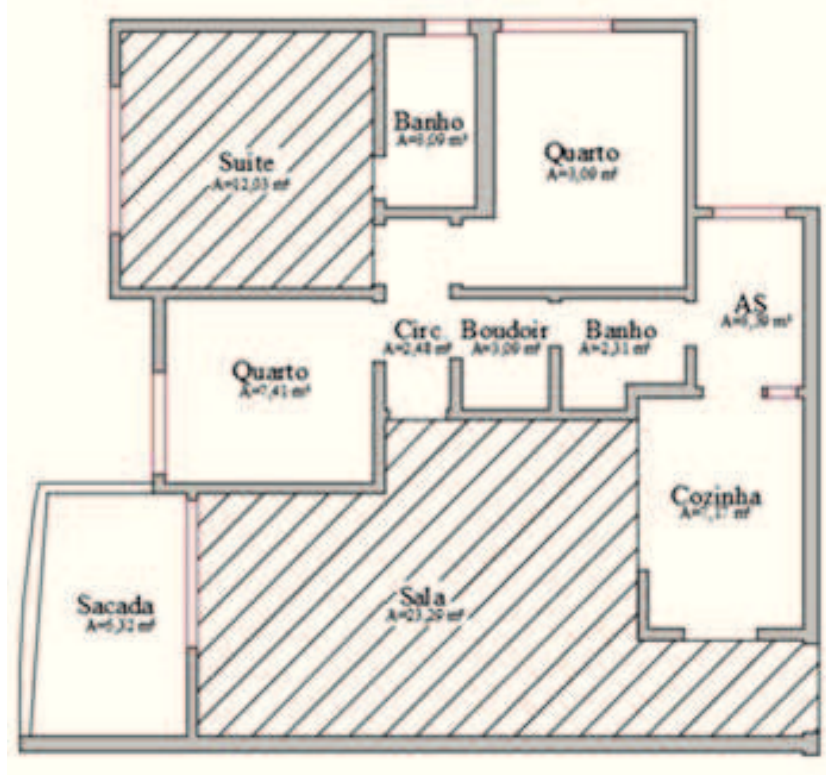

Fonte: elaborado pelos autores a partir de dados fornecidos pela construtora.

Todos os apartamentos possuem condicionador de ar quente e frio na suíte e na sala, a exceção é o apartamento $C$ que não possui ar condicionado na sala. Durante todo o tempo das medições não se teve controle do acionamento ou não destes equipamentos. Todas as aberturas dos ambientes de grande permanência são com sistema de correr (janelas dormitórios e porta janela da sala).

A Figura 04 mostra: a localização dos apartamentos nos quatro blocos que fazem parte do condomínio analisado; a orientação solar dos apartamentos; e também os critérios de designação dado aos apartamentos (A, B e C). Observa-se ainda que os apartamentos são todos de canto.

A Figura 05 apresenta um croqui do sistema construtivo de parede externa, cujos dados foram obtidos junto com a construtora. As dimensões dos componentes da parede são: tijolo com 0,135m x 0,185m x 0,185m; espessura da argamassa de 0,01m; e espessura do reboco: 0,015m.
Figura 04: Croqui de localização dos apartamentos nos edifícios.

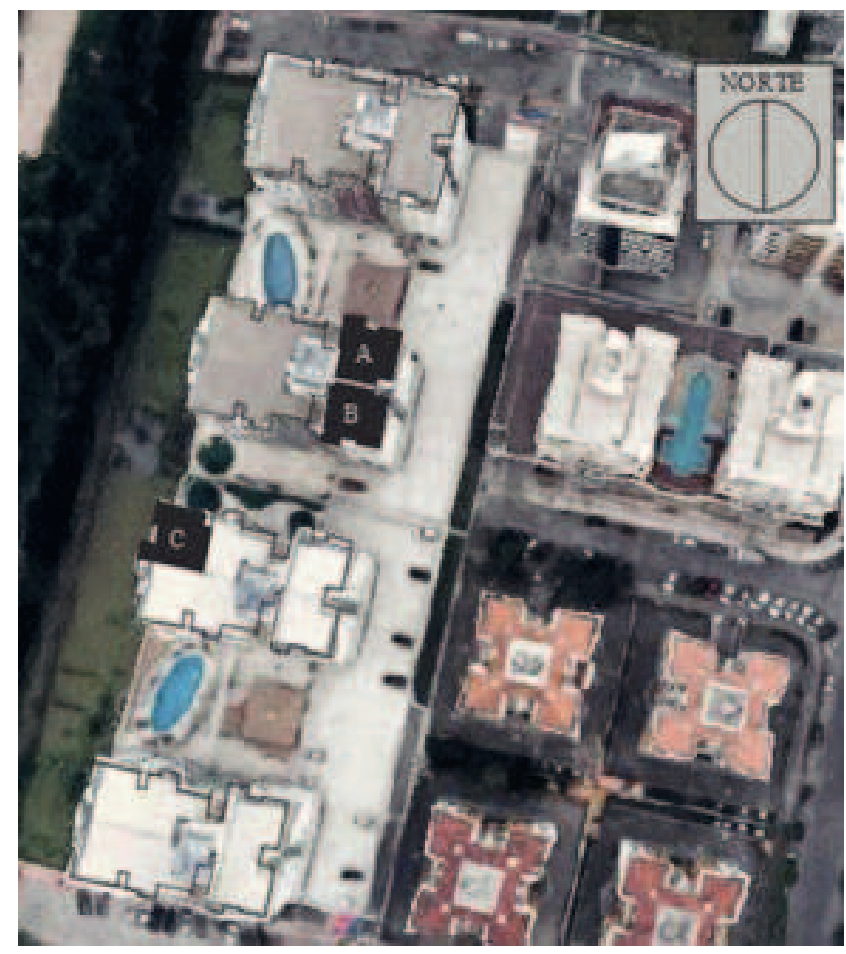

Fonte: elaborado pelos autores sobre imagem Google Earth.

Figura 05: Croqui do sistema construtivo da parede externa.

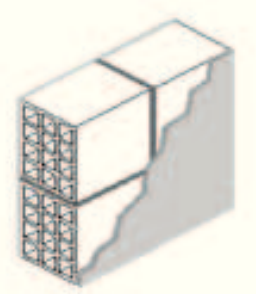

$$
\begin{gathered}
\text { Transmitância térmica } \\
\text { "U" }=2,13 \mathrm{~W} /\left(\mathrm{m}^{2} \cdot \mathrm{K}\right) \\
\text { Capacidade térmica } \\
\text { "C" } \mathrm{C}=151,67 \mathrm{~kJ} /\left(\mathrm{m}^{2} \cdot \mathrm{K}\right)
\end{gathered}
$$

Fonte: elaborado pelos autores.

\subsection{Medições das temperaturas}

Para a aquisição dos dados de temperatura e umidade relativa do ar, foram utilizados três modelos diferentes de aquisição de dados (data loggers) da Onset Corporation, conforme Tabela 02. Os dados coletados foram transferidos pelo software próprio do equipamento a um computador pessoal, para posterior tratamento e análise. Para a medição das temperaturas externas foi utilizado o modelo U23-001, ideal para ambientes externos, e colocado na parte externa da sacada do Apartamento C. Os outros equipamentos foram dispostos sobre móveis de madeira, buscando sempre a centralidade dos ambientes e evitando serem colocados próximos a paredes que tenham contato com o exterior. 
Tabela 02: Descrição dos sistemas de aquisição utilizados para medição das temperaturas

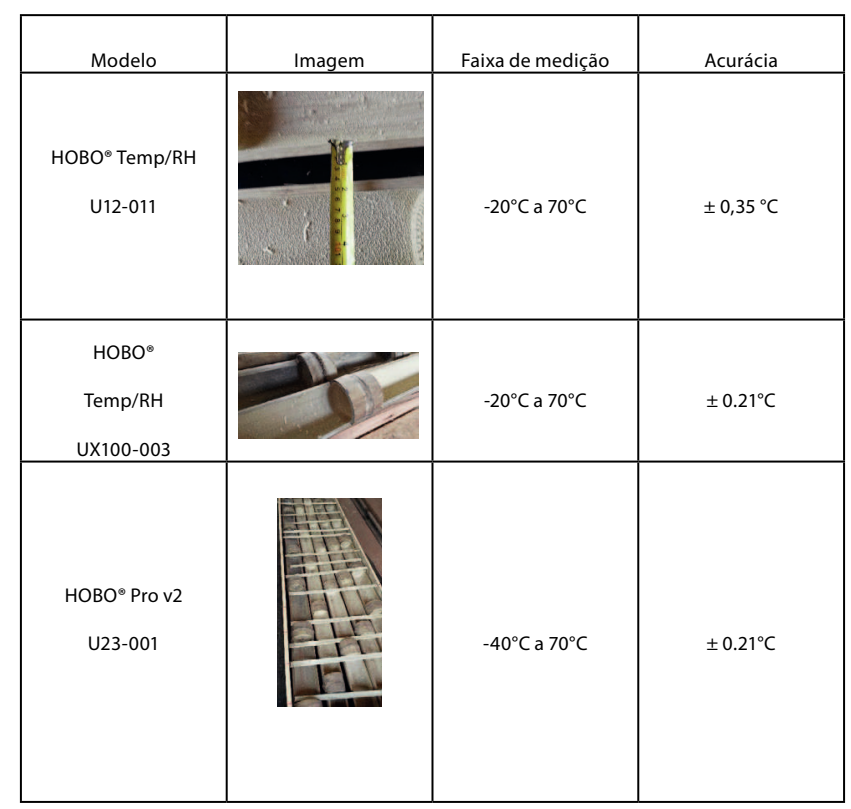

Fonte: Elaborado pelos autores a partir dos manuais dos equipamentos.

Os equipamentos foram programados para fazer a aquisição de dados de quinze em quinze minutos de temperatura e umidade relativa do ar dos ambientes internos e externo, durante o período de um ano (julho de 2015 a junho de 2016), e posteriormente foi feita a média hora a hora numa planilha do Excel. A cada dois meses fazia-se uma visita aos moradores para baixar os dados monitorados em um notebook com software próprio da Onset Corporation, e uma nova programação nos equipamentos era feita. Esta visita periódica tinha como intuito verificar a funcionalidade dos equipamentos e evitar perda de dados durante um grande período de tempo. Mesmo com todo esse cuidado, durante o mês de dezembro e janeiro perdeu-se os dados de medição do ambiente externo, por erro de programação no equipamento. Por isso para este período foram utilizados os dados climáticos do Laboratório de Engenharia de Processos de Conversão e Tecnologia de Energia (LEPTEN) do Departamento de Engenharia Mecânica da UFSC.

\subsection{Determinação dos percentuais de horas em conforto}

Através dos dados horários medidos in loco gerou-se um arquivo próprio para leitura pelo Analysis Bio (arquivo texto com extensão .try), para cada um dos ambientes que foram monitorados. Após, elaborou-se as cartas bioclimáticas para cada ambiente interno e do ambiente externo. O programa gera além das cartas psicrométricas com as temperaturas e umidades plotadas sobre as zonas bioclimáticas, relatórios em forma de texto e histogramas que fornecem dados percentuais das horas de conforto, desconforto e principais estratégias construtivas em função dos dados climáticos.

\section{RESULTADOS}

As duas principais recomendações para obtenção de conforto para Florianópolis, segundo a carta bioclimática de Givoni, é a ventilação para evitar o desconforto por calor, e massa térmica com aquecimento solar para evitar desconforto por frio.

Com relação a ventilação, os apartamentos atendem ao que é preconizado pelo RTQ-R de abertura mínima de $8 \%$ da área de piso, visto que atendem ao Código de Obras de Florianópolis, e são todas esquadrias de correr nos dormitórios e sala. Com relação a ventilação cruzada, por terem aberturas em fachadas com orientação diferentes, a unidade habitacional, no caso os apartamentos, atendem também a esta recomendação.

Com relação a massa térmica, o sistema construtivo das paredes dos apartamentos monitorados (Figura 04) atende tanto os aspectos de transmitância térmica quanto de capacidade térmica da NBR 15.575 (Tabela 01). Com relação ao ganho térmico solar, somente o apartamento $B$ é que tem fachadas a leste e sul, sendo que a suíte e a sala tem aberturas orientadas a sul. $\mathrm{O}$ apartamento $\mathrm{A}$ possui os ambientes monitorados com aberturas a norte, e o apartamento $C$ possui aberturas da sala e suíte com orientação a oeste.

As cartas bioclimáticas de Givoni com a plotagem dos dados de temperatura e umidade do período de 01 de julho de 2015 a 30 de junho de 2016, do ambiente externo (Figura 06) e das suítes e salas dos apartamentos, são apresentados a seguir (Figuras 07a, 07b, 08a, 08b, 09a, 09b). Nestas figuras também se apresenta os resultados percentuais de conforto e desconforto obtidos através dos relatórios do software Analysis Bio, assim como as principais estratégias bioclimáticas.

A primeira observação a ser feita é com relação as condições de conforto externa do período das medições (Figura 06) com o ano climático de referência (TRY) em Florianópolis (Figura 02). No período desta pesquisa, a porcentagem de horas de conforto foi 29,3 pontos percentuais superior do que as horas de conforto no TRY. A porcentagem de horas de desconforto por calor foi muito próxima, $38 \%$ no TRY e $39,6 \%$ no ano de desta pesquisa. As horas em desconforto por frio foram $41 \%$ no TRY, e nas medições pouco menos da metade, $20,1 \%$ das horas em desconforto por frio. Desta forma pode-se dizer que o ano de dados 
desta pesquisa, apresentou um ano com temperaturas mais elevadas no período mais frio, se comparadas com as temperaturas do ano climático de referência.

Através dos resultados gerados pelas cartas bioclimáticas com as temperaturas internas dos apartamentos, pode-se verificar que as horas de conforto nos ambientes internos tendeu a ser superior entre 8,7 pontos percentuais e 25,9 pontos percentuais acima da porcentagem de conforto em relação ao ambiente externo. A única exceção foi a suíte do apartamento C, que apresentou 4,3 pontos percentuais de horas de conforto abaixo do que as horas de conforto do ambiente externo. Quando se analisa o desconforto por frio, o que se observa é uma diminuição da porcentagem das horas de desconforto dos ambientes internos com relação ao ambiente externo. Internamente variou de $0,5 \%$ a $6,1 \%$ as horas de desconforto por frio, enquanto externamente a porcentagem foi de $20,1 \%$ de
Figura 06: Carta Bioclimática de Givoni com dados externos de temperatura e umidade plotados do período de julho de 2015 a junho de 2016.

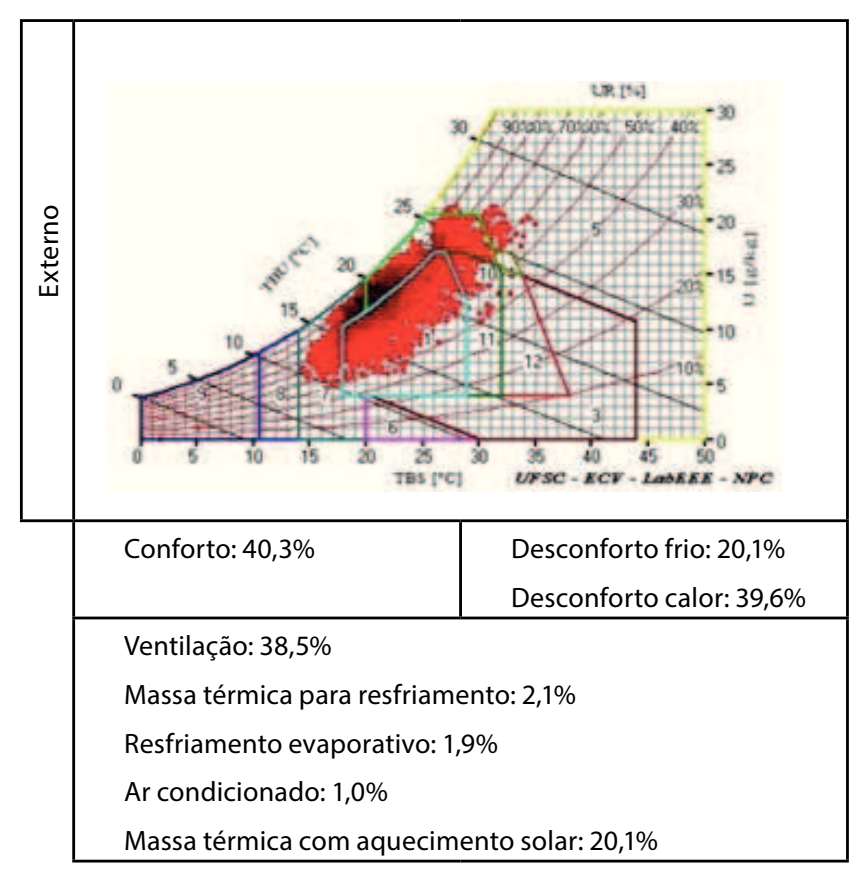

Fonte: elaborado pelos autores

Figura 07: Carta Bioclimática de Givoni com dados de temperatura e umidade plotados da sala (a) e suíte (b) do Apartamento A no período de julho de 2015 a junho de 2016.

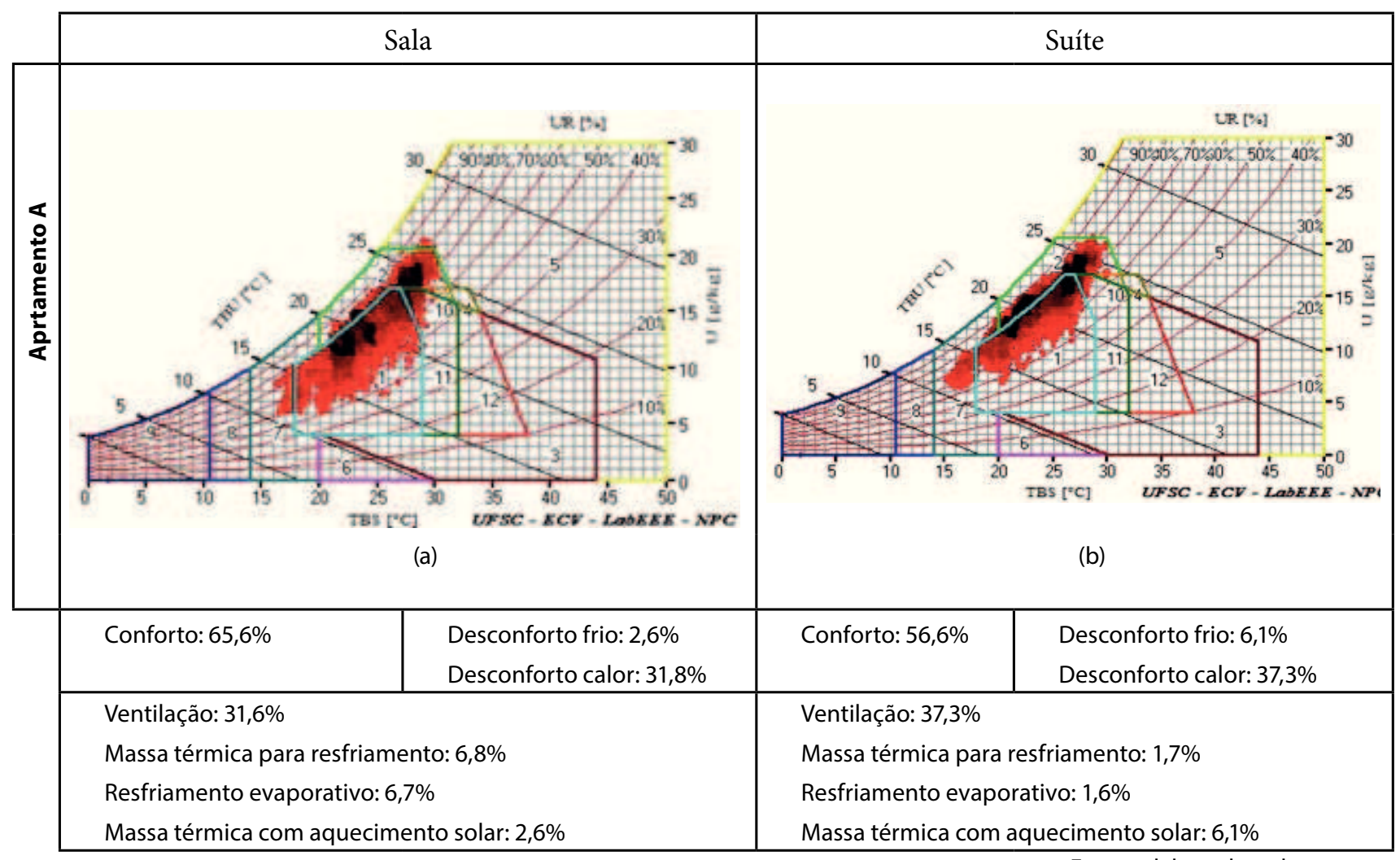

Fonte: elaborado pelos autores 
Evidencia-se que nos períodos frios as edificações tendem a ficar com as aberturas externas mais fechadas, tendo menor relação da temperatura interna com a externa, além do ganho térmico interno pela ocupação e equipamentos. Mas de forma geral, o fato da edificação atender aos requisitos de transmitância e capacidade térmica da NBR 15.575 fez com que o comportamento térmico interno de todos os ambientes acabasse com melhor desempenho no período frio.

A sala e a suíte do apartamento B tem aberturas com orientação solar sul, enquanto estes mesmos ambientes no apartamento A tem orientação solar norte. Era de se esperar que os dois ambientes internos do apartamento $B$ tivessem a porcentagem de horas com a indicação de massa térmica com aquecimento solar menores do que o apartamento $A$, que supostamente recebe mais radiação solar no inverno. Aqui vale salientar que, a moradora do apartamento $\mathrm{A}$ informou que evita ligar o ar condicionado. Enquanto nas visitas que foram feitas para acompanhar o monitoramento no apartamento $\mathrm{B}$, todas as vezes o ar condicionado na sala estava ligado, inclusive no inverno.

Destaca-se também a mancha de pontos linear e vertical na zona de aquecimento artificial e massa térmica com aquecimento solar da sala do Apartamento C (Figura 09a).
O equipamento que estava neste ambiente precisou ser trocado porque parou de funcionar. Possivelmente os dados que apresentaram distorções foram anteriores a falha do data logger, pois aparecem valores com temperatura do ar interno inferior a $10^{\circ} \mathrm{C}$, sendo que externamente as temperaturas não baixaram de $15^{\circ} \mathrm{C}$.

Com relação ao desconforto por calor, o que se observa é que apesar da existência de condicionadores de ar em todos os ambientes analisados, três deles apresentaram mais horas de desconforto de calor que o ambiente externo no mesmo período. Sendo que nos três ambientes (Sala e Suíte apartamento A, Sala Apartamento C) que apresentaram menor quantidade de horas de desconforto por calor que o ambiente externo, este valor foi somente entre 2,3 a 8,5 pontos percentuais melhor. Os dois ambientes do apartamento B apresentaram valores 3,5 (sala) e 10,0 (suíte) pontos percentuais acima das 39,6\% de horas de desconforto por calor do ambiente externo. A suíte do apartamento $C$ foi a que apresentou maior horas de desconforto por calor, $62,8 \%$ das horas do ano. Ou seja, mais da metade das horas do ano a suíte tinha condições climáticas internas, que segundo a carta bioclimática de Givoni, precisaria de algum tipo de sistema de resfriamento. Destas horas, $61 \%$ caíram na região onde a ventilação

Figura 09: Carta Bioclimática de Givoni com dados de temperatura e umidade plotados da sala (a) e suíte (b) do Apartamento C no período de julho de 2015 a junho de 2016.

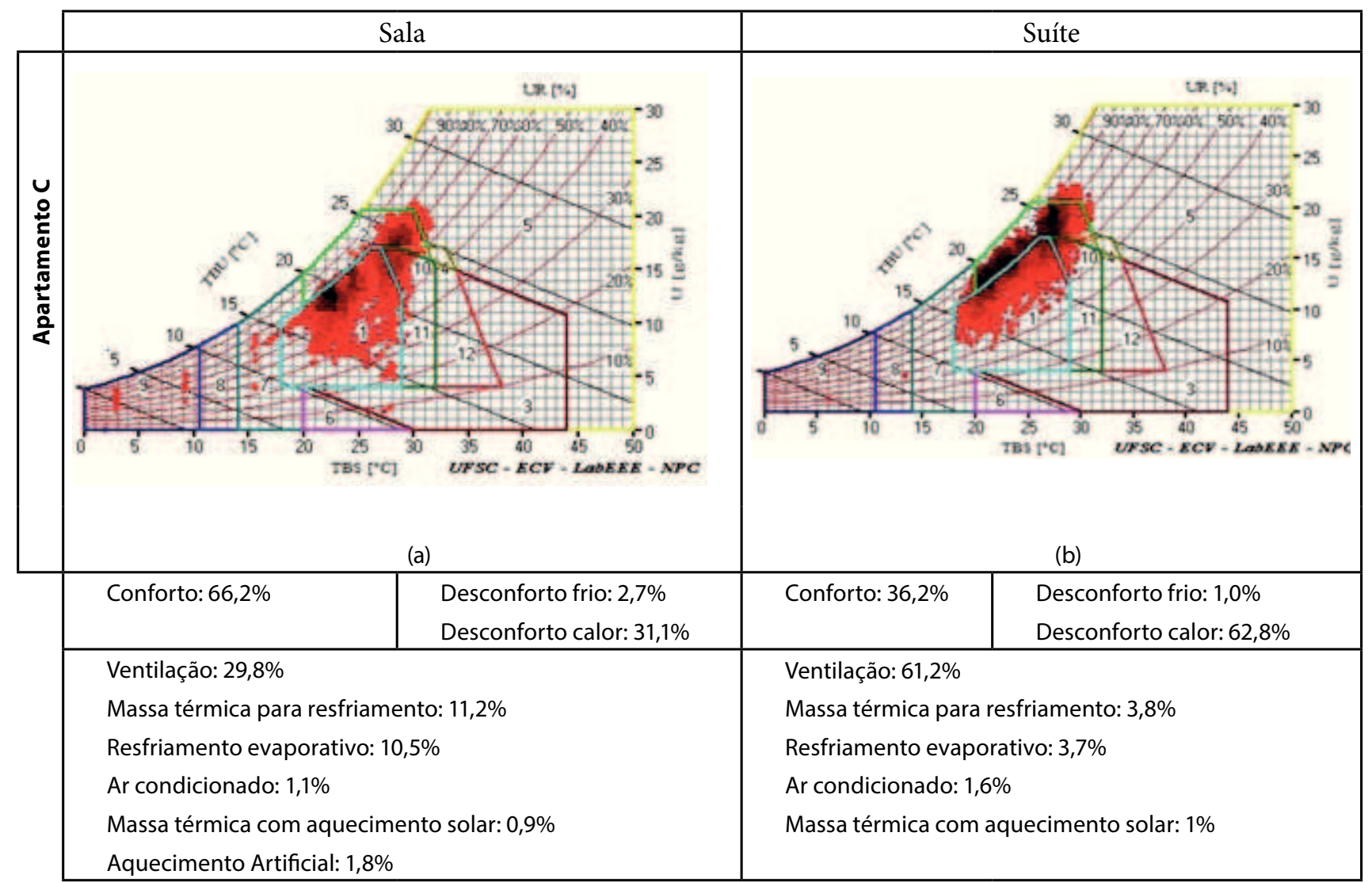


garantiria o conforto. Vale salientar que a suíte do apartamento $C$ tem parede sem abertura a norte, e parede com abertura a oeste. Assim, num período sem ocupação, o ganho de calor externo sem a possibilidade de perda de calor por ventilação, resultará num aumento da temperatura interna.

\section{CONCLUSÕES}

O objetivo deste trabalho está na comparação do conforto térmico em apartamentos em uso frente ao comportamento térmico do ambiente externo. Nos apartamentos monitorados durante um ano o que se verificou foi que a edificação, e possivelmente o comportamento dos usuários, garantiu que os ambientes apresentassem percentualmente uma melhora no conforto térmico se comparado ao conforto do ambiente externo.

Os critérios de uso de equipamentos de condicionamento de ar e ocupação da edificação foi levantado em uma primeira entrevista com os moradores, mas não foi feito nenhum monitoramento do uso dos condicionadores de ar ou da ocupação dos apartamentos durante a pesquisa.

O que se observa é que o desconforto por frio é amenizado nas edificações, mas o desconforto por calor, no ano analisado, foi superior nos ambientes internos do que no ambiente externo. Especificamente com relação ao apartamento $C$, o casal de moradores por serem aposentados e viajarem muito, possivelmente mantiveram o apartamento fechado nos períodos quentes, não se utilizando da ventilação natural.

\section{AGRADECIMENTOS}

Ao CNPq pelas bolsas acadêmicas, ao IFSC pelos recursos disponibilizados ao projeto, ao LabEEE pelo empréstimo de parte dos equipamentos utilizados, a construtora que nos auxiliou de diversas formas, mas principalmente nos colocou em contato com os moradores. Aos moradores dos apartamentos que tão gentilmente nos possibilitaram fazer as medições em seus lares. Ao prof. Cleide Cedani Andrade, quem possibilitou iniciar esta pesquisa, nosso eterno agradecimento.

\section{REFERÊNCIAS}

ABNT - ASSOCIAÇÃO BRASILEIRA DE NORMAS TÉCNICAS. NBR 15.220-3: Desempenho térmico de edificações - Parte 3: Zoneamento bioclimático brasileiro e diretrizes construtivas para habitações unifamiliares de interesse social. Rio de Janeiro: ABNT, 2003.
ABNT - ASSOCIAÇÃO BRASILEIRA DE NORMAS TÉCNICAS. NBR 15.575-1: Edificações Habitacionais Desempenho parte 1: requisitos gerais. Rio de Janeiro: ABNT, 2013.

AMERICAN SOCIETY OF HEATING REFRIGERATING AND AIR ENGINEERS CONDITIONING (ASHRAE). ASHRAE 55-2010: Thermal Environmental Conditions for HumanOccupancy. Atlanta, 2010.

CÂMARA MUNICIPAL DE FLORIANÓPOLIS. Código de Obras. Lei Complementar No 060/2000, de 28 de agosto de 2000. Disponível em: <http://www.cmf.sc.gov.br/legislacao> Acesso em 05 de outubro de 2015.

CHAVES, V. L. et al. Análise de conforto térmico para diferentes estratégias de melhorias climáticas em salas de aulas: Comparação entre dados técnicos e a percepção dos usuários. In: Encontro Nacional de Tecnologia do Ambiente Construído, 16. 2016, São Paulo. Anais. Porto Alegre: ANTAC, 2016.

FROTA, A. B.; SCHIFFER, S. R. Manual do conforto térmico. 4 ed. São Paulo: Studio Nobel, 2000.

GIVONI, B. Comfort Climate Analysis and Building Design Guidelines. Energy and Buildings, v.18, n.1, p.1123, 1992.

GOULART, S. V. G et al. Bioclimatologia aplicada ao projeto e edificações visando o conforto térmico. Relatório Interno: NPC, UFSC, Florianópolis, 1994.

GOULART, S. V. G. LAMBERTS, R. FIRMINO, S. Dados climáticos para projeto e avaliação energética de edificações para 14 cidades brasileiras. 2. ed. Florianópolis: Núcleo de Pesquisa em Construção/UFSC, 1998.

INSTITUTO NACIONAL DE METROLOGIA E QUALIDADE INDUSTRIAL. Regulamento Técnico da Qualidade para o Nível de Eficiência Energética de Edificações Residenciais (RTQ-R). Rio de Janeiro: INMETRO, 2012. Portaria n. 18.

MIRANDA, S. A. et. al. Processamento de arquivo climático para avaliações de conforto ambiental em Cuiabá - MT. In: Encontro Nacional de Tecnologia do Ambiente Construído. Anais. Porto Alegre: ANTAC, 2010. 
LAMBERTS, R.; DUTRA, L.; PEREIRA, F.O.R. Eficiência Energética na Arquitetura. 3 ed. Rio de Janeiro: Eletrobras/ Procel, 2014.

LAMBERTS, R. et al. Towards a brazilian standard on thermal comfort. Disponível em: <http://www.labeee. ufsc.br/sites/default/files/publicacoes/relatorios_pesquisa/RP_Towards_a_Brazilian_Standard_Complete_ Version2013.pdf>.

RUPP, R. F.; VÁSQUEZ, N. G.; LAMBERTS, R. A review of human thermal comfort in the built environment. Energy and Buildings. v. 105, p. 178-205, jul. 2015.

SOUZA, H. A.; RODRIGUES, L. S. Ventilação natural como estratégia para o conforto térmico em edificações. REM: Revista Escola de Minas. v. 65(2), p. 189-194, abr. jun. 2012. 